\title{
How to Show a National Cuisine: Food and National Identities in the Masterchef Kitchen
}

\author{
Luca Rimoldi \\ PhD in Anthropology, University of Milano-Bicocca \\ Email: luca.rimoldi@unimib.it
}

\section{Doi:10.5901/ajis.2015.v4n2p257}

\begin{abstract}
In this article, I analyse some aspects that characterise the relationship between food preparation practices and national identities in the first American, Spanish and Italian edition of the Masterchef international television format. The article is divided into two parts: in the first one, I perform a comparative analysis of the representation and the spectacularization of national identities in terms of how they are conveyed in the Masterchef kitchens. Conversely, in the second part, I highlight the aspect of self-storytelling through a specific perspective on the work of the chef and its media representation by relating it to the economic and employment crisis that has affected the West at various levels in recent years.
\end{abstract}

Keywords: Anthropology, Media, Food, Masterchef, National Identities.

\section{Introduction}

Anthropological studies have pointed out that complex and stratified processes, including images and various kinds of representations in the political and social sphere, are traceable in what is defined as the creation of a national identity (Herzfeld, 1997; Fabietti, 2003; Remotti, 2001). In general terms, I consider national identity as a symbolic and cultural construction continually negotiated both within and outside the nations. In this sense, the concepts of 'imagined communities' (Anderson, 1983) and of 'invention of tradition' (Hobsbawam, Ranger, 1983) are proven indispensable heuristic tools to investigate the smooth practices of national identity construction. Studies on food have also drawn attention to the symbolic role that recipes, the preparation of dishes, their ingredients and their aesthetics can have in negotiating the identity of a community. As Arjun Appadurai (1988) has shown in his analysis of the Indian context, the creation of a national cuisine through cookbooks and recipe books published between 1960 and 1980, has contributed significantly to what the same Appadurai called 'civilising processes', to paraphrase Norbert Elias (1978). In the words of the anthropologist, Indian cookbooks "reflect shifts in the boundaries of edibility, the proprieties of the culinary process, the logic of meals, the exigencies of the household budget, the vagaries of the market, and the structure of domestic ideologies" (Appadurai, 1988: 3).

In India, the process of building a national cuisine through textualization was triggered in the pre-industrial and postcolonial period, although there was no shortage of previous culinary traditions incorporating moral values and medical knowledge. The authors of the cookbooks subject to Appadurai's anthropological analysis are almost all middle class women and their texts seem to create what is defined as seductiveness of variety.

Currently, this seductiveness seems to have prevailed in other contexts through other means of communication, such as international television formats. In this sense, a good example is the Masterchef television format, which was launched in the UK in the early Nineties, remained within the confines of the island for over a decade, and then spread almost globally ${ }^{1}$ from the second half of the first decade of the new millennium. In general terms, the program can be defined as a culinary talent show where a number of contestants compete in the preparation of several dishes; depending on three judges' final decision, the latter determine whether the participants stay in the game and thus have a chance of

1 The programme established itself in several countries in different years: Australia, Belgium, Croatia, Denmark, Finland, France, Germany, Greece, India, Indonesia, Italy, Ireland, Israel, Malaysia, Netherlands, New Zealand, Norway, Peru, Philippines, Portugal, Romania, Spain, Sweden, Turkey, and Ukraine. 
winning the final prize: a sum of money and the option to publish a recipe book ${ }^{2}$. The impact that this programme has had and continues to have on culinary practices is demonstrated, among other things, by the pervasiveness that, over the years, has taken Masterchef beyond television and ensured its successful launch on smartphones (through dedicated apps) and in bookshops. Indeed, it is easy to observe how the references to Masterchef are somehow monopolising the public's attention just by looking around the food section of any bookshop.

This article discusses some aspects that emerge in the first editions of Masterchef Italy (2011), Masterchef USA (2010), and Masterchef España (2013) ${ }^{3}$ and shows how the national identities of the individual countries have been shaped through the spectacularization of food preparation - and therefore through the work carried out in television kitchens. As Riccardo Ciavolella reminds us:

"On the one hand, anthropologists have studied the imaginary realities produced by the media, which are often confused with cultural studies. On the other hand, preserving its empirical tradition, on a cultural level, they have focused on the methods of reception and internalisation of the flows of values, symbols, methods and imaginary realities conveyed by the media, especially at a global scale (...)" (Ciavolella 2013: 83).

Each format should be analysed in-depth to highlight the dynamics and the implications that television programmes create in the impact with the social fabric which is undoubtedly composed and stratified differently in every social reality (Ginsburg, Abu-Lughod, Larkin 2002; Painter, 1994), however, I am sure that the complex culinary repertoire that Masterchef offers in the editions under examination, can clarify and exemplify the kind of fragmentation and configuration of culinary practices that the programme produces in the different national versions. If the cookbooks referred to by Appadurai are culturally and socially characterised historical products, created in a specific country, the Masterchef format is interpreted and absorbed more artificially at a local level. It is indeed this aspect, which, in my opinion, is particularly important and, in some way, justifies a comparative approach focusing on the construction of the television product itself rather than on its social and cultural consequences. If the Indian cookbooks have helped create a national cuisine, conversely, the food cooked in the Masterchef kitchens and how it is prepared, have shaped the imagination through a pervasiveness that goes beyond the competition itself, and which, in my opinion, strives to invent a tradition by representing it. Moreover these processes take place within the television rhetoric of representation, in a virtual space where is constructed an image of a national identity, which seems to use food, its consumption and culinary practices to tell the stories of the contestants with special attention to the kitchen work aspects. The article is divided into two parts: in the first one, I perform a comparative analysis of the representation and the spectacularization of national identities in terms of how they are represented in the first American, Italian and Spanish editions and conveyed by culinary practices. Conversely, in the second part, I highlight the aspect of self-storytelling through a specific perspective on the work of the chef and its media representation by relating it to the economic and employment crisis situation that has affected the West at various levels in recent years. If the Indian cuisine texts analysed by Appadurai also described some of the practices of food preparation as well as the recipes, in the contemporary media reality these practices are staged: I am convinced that it is not just the dish that becomes a symbol of a specific national identity but also the gestures, movements and stories that lead to its preparation and therefore, in this sense, kitchen work plays a central role.

\section{Media Recipes for a National Cuisine}

If, as claimed by Carlo Cracco, - internationally renowned chef and judge of the Italian edition of Masterchef - "la cucina non è fashion, la cucina è cultura" (cooking is not fashion, cooking is culture), it thus seems interesting to explore some of the features brought to the fore in the television representation of this "culture".

In the first few minutes of the first episode of the Italian edition of the programme, as a set of images of prepared dishes are alternated with pictures of the television studios where the programme is staged, a voiceover announces: "There is a show that has changed the television cooking methods worldwide. Broadcast in 145 Countries, a big success everywhere, it is the most spectacular cooking competition. A passion that unites all peoples finally has its own

\footnotetext{
2 The statements by Pepe Rodríguez, a judge in the Spanish edition of the programme, nevertheless emphasise that the real reward for the winner of Masterchef does not have a mere economic or material value, it rather pertains to a symbolic universe of moral value.

${ }^{3}$ The reasons that led to the decision to analyse the first editions in these countries will be clarified in the course of the discussion. In general terms, the Spanish edition is the most recently concluded first edition relative to the time when I started writing this paper; the Italian and American editions share both the narrative structure in the strict sense and the presence of the same judge. 
programme: Masterchef".

The transition from the kitchen to its television representation is not a neutral process; the transition in the media world brings with it an acceleration of preparation time and a reduction in the spaces. The programme participants move and cook in adjacent areas and, from episode to episode, they run to a warehouse where they come out filled with a variety ingredients that will transform the dishes to be submitted to the judges. But, as in many television programmes, the size of the space during image editing is much more fluid: the Spanish edition of the programme displays images of chefs busy preparing dishes, images of the selections of competitors meaningfully alternated with scenes of the Spanish army in military actions. On the highest part of the entrance of the General Menacho Base in Badajoz, the image which concludes the image edit, the inscription "Todo por la patria" (Everything for the country). The national statement seems to be presented both by national culinary practices and by the reference to the army and its role in safeguarding national unity. Spanish Masterchef applicants seem to be given the task of defending the symbolic boundaries of the country through the preparation of national dishes 4 .

Even the time aspect is smoothly represented. Indeed, in the third episode, the contestants of the Spanish edition have to cook for the cast of Isabel, the television series which tells the story of the events relating to the union of the two most important crowns in Spain at the end of the fifteenth century from historical fiction perspective. Through the marriage of Isabella I of Castile and Ferdinando II of Aragon, and with the conquest of the territories occupied by the Arabs and the reform of the State, a decisive step is taken towards the reunification of the Iberian territory, which has always been characterised by the presence of centrifugal and centripetal nationalism. "Put yourselves in the shoes of the knights of Castile", says Queen Isabella (the actress Michelle Jenner) to the Masterchef contestants, thus reinforcing the role of defenders of national borders already attributed to contestants in the first episode of the first season.

Returning to Italy, Jack Goody (1998) had noticed how it was meaningless to talk of a strong differentiation between what he calls "high" and "low" cuisine; the regional cuisines are the high Italian cuisines, and therefore, it would seem inappropriate to talk of a high trans-regional cuisine. As announced by the voiceover in the first episode of the Italian series:

"(...) cooking is a very Italian passion, made of fragrances, flavours and traditions. From North to South, thousands of aspiring chefs have waited in line for hours with one goal: to win the title of first Italian Masterchef".

It is not surprising the structure of the competition itself was built starting by defining the differences between the regional cuisines that Italian cuisine is made of. Thus, we find that the proposed topics for the invention tests of the Italian edition include, for example, "welcome to the South" (episode 1) or that the "typical ingredients of the Italian mountains" are proposed (episode 11); also, in this type of test, there is always the homemade pasta preparation trial. Indeed, in the seventh episode, the handling of the ingredients for the preparation of one of the most representative dishes of Italian cuisine, is tied to a discourse of family memory and nostalgia; Vito, an Italian comedian invited ad hoc specifically due to the fact that he originates from the region of Emilia-Romagna, tells the following story to the contestants and to the judges:

"During the World Word II, my grandmother made homemade pasta, noodles, cooked them in the pot, and if at that time the air-raid alert sounded, my grandmother did not leave the noodles, she used to say: 'I have to stay here to look after the noodles, you go to the shelter, when you get home the soup will be on the table; so homemade pasta a serious matter. (...) [My favourite stuffed pasta] is the tortellini my mother makes, but also the tortelloni my father makes, he went to pick nettles (...) which are scrumptious, prepared with ricotta cheese, parsley and a pinch of garlic, the pinch of garlic in the ricotta gives the tortellone that sprint which makes the tortellone rise up in the plate and end up in your mouth by itself. (...) at home, lasagne was green, with white sauce combined with meat sauce, not layered and should not be eaten right away, it is like meat, it should be left to rest a while to let the pasta compact at the end of cooking; it must be raised, you have to wait a while (...)".

As I said, the Italian and US formats have the same structure, there are many similarities between the two programmes: the types of selection tests the contestants have to take, for example, cutting onions or the preparation of an dish where an egg is the protagonist, the identification of the ingredients of a dish that the contestants taste

4 Precisely in the General Menacho Base in Badajoz, the contestants of the first Spanish edition face their first team test: cooking for 151 soldiers of the Brigada de Infantería Mecanizada "Extremadura" XI. The Italian and the American editions also followed a similar script, where external tests were staged respectively on a navy ship and in a military base near San Diego. 
blindfolded, guessing the names of some raw materials used in cooking, as well as the presence of the same judge, Joe Bastianich.

But there's more! Indeed, in the narrative structure of the first editions of the programme aired in the two countries a few years apart, there are many expressions that both American and Italian judges address to competitors such as, for example, "You three have totally different backgrounds, but you also have one thing in common, you are all going to continue!", or "untie your apron ${ }^{5}$ and tie it back on even tighter".

However, unlike the Italian edition, from a culinary practice perspective, the American show seems to be a response to the multi-ethnic social composition of the programme's target audience. If, as I said previously, in Italy, the first edition of Masterchef was presented as a showcase of what is identified as a traditional cooking, in the US, the preparation of dishes that represent many culinary traditions seems to want to present the composite local social stratification and, secondly, to encourage the public to learn and to explore the tastes and recipes of other groups. Just think about the fact that the theme of the first Invention Test of this edition is non-specific "Chinese food".

Appadurai argues that "Food taboos and prescriptions divide men from women, gods from humans, upper from lower castes, one sect from another (...).Food is believed to cement the relationship between men and gods, as well as between men themselves " (Appadurai, 1988: 10), however, in the media representation of the work of chefs, individual beliefs seem to be substitute by a roll-up-sleeves logic (Marrone, 2013). In the mystery box test in episode 8, the voiceover - that introduces the viewer to the situation the contestants are in - announces: "to be a Masterchef, you have to work with fresh ingredients but one of these ingredients is fresher than one of the competitors can handle". Removing the mysterious boxes from their workbenches, the competitors are faced with a number of crabs, which have to be thrown alive into boiling water for cooking. The images of an interview with Sheetal, a teacher of Indian origin (37 years old in 2010) break the narrative continuity of the scene; the woman says she was raised Hindu and that her religion does not allow her to take an animal's life: "I grew up in a vegetarian family, we do not go hunting, fishing. I have never killed anyone before". The staging of the crisis of values of the contestant - represented by the fragment of life story and her tears inside the kitchen - is followed by the contestant's exit from the main stage. The judge Gordon Ramsay reaches her in one corner of the television studio, and asks her why she left her position; the judge's offer to - "throw it in the water for [her]" - is followed by the contestant's refusal. After a brief exchange with Ramsay, Sheetal says, "I have to grow up a little "' and, after a few scenes, "if I really have to kill an animal, I will do something amazing with him". This type of standardisation driven by the preparation of food on television resurfaces at different times throughout the programme and in some ways, it seems to be designed to go beyond some social mechanisms.

\section{Cooking on Television in a Time of Crisis}

If the transition from the kitchen to its media representation is never neutral, the same could be said for the working aspect in which it is inscribed. There is no doubt that the culinary professions on television went through an expansion stage so obvious, as to require a review, which, in the context of Masterchef, is manifested in the aspirations of the contestants. These aspirations, stuffed with rhetoric that I will try to explain in the pages that follow, seem to trace the idea that, in a world of work marked by employment crisis, the revaluation of what could be defined as "skilled craftsmanship" can make a chef's work a potential new aspiration ${ }^{6}$. If, as Appadurai says, "Many of the new cookbooks emphasize that they are specifically designed to resolve shortages of time and money in urban settings. They therefore frequently offer menus, shortcuts, and hints on how to get more out of less". (Appadurai, 1988: 8), the Masterchef kitchen is not designed to churn out dishes that the public can reproduce, it is rather an anthropologically interesting place for understanding some of the dynamics related to the media work of food preparation.

The staging of the work of chefs in Masterchef seems, at a first level of analysis, to answer the consideration that the sociologist Richard Sennett developed a few years ago (Sennett, 2008); in the contemporary western world, outsourcing processes of the work was overshadowed that ability characterised by the work of craftsmanship: knowledge and techniques for transforming a raw material into a product that does not suffer from the detachment of the product

\footnotetext{
${ }^{5}$ The apron on which the programme logo is printed symbolically unites all contestants: it is distributed to the most deserving during the selection and must be returned when the contestant leaves the television challenge.

${ }^{6}$ Recently there has been a significant increase in enrolment in Italian hotel and catering schools: according to the Coldiretti data, in 2013, 46.000 young people who hoped to become a chef started this training course. In March 2013, the Ministry of Education, University and Research reported a 9\% increase in enrolment in vocational schools with specialisation in "food and wine, hospitality, hotels".
} 
itself. Masterchef therefore seems to stage, or rather mediate, precisely this return to an "immediate" work. If, according to Sennett, the craftsman is a representative figure of that condition that brings people to make every effort in the things that they do (Sennett, 2008), in the Masterchef kitchen, the public sees, following a narrative, one of the participants "become" the first Masterchef in its country. According to Gianfranco Marrone, the deepest meaning of Masterchef would be to "convey a distorted image of gastronomy, where the pleasure of food and conviviality are banned for the benefit of the culinary boldness of the average man or that it is equivalent to the rampant struggle of last-hour reality TV" (Marrone, 2013: 237-238). The rhetoric of haute cuisine or of cooking as a means of knowledge of the Other would be associated with that typical of the middle class everywhere, the passion and commitment as an engine of change in an unsatisfactory situation.

In the first episodes of all three editions considered the potential contestants utter sentences in different languages that refer to the attempt, through participation in the programme, to change their lives, fulfil their dream, live their passion $^{7}$; thus a desire to change their condition is revealed. The situation object of the desire for change of Masterchef contestants of all editions under analysis is, in the first place, the work situation and the means of passion. The careers, along with age and - in the case of Spain and the US - the region or country of origin, are recalled constantly through overlaid text that appears when the contestants are asked to comment, in a game of crossing time dimensions, on the episodes of the narrative that the public is following at that time.

The Italian and US editions are those for which aspects of the personal life of competitors emerge more heavyhandedly. The media concept of the profession of chef is counterbalanced by the staging of the stories of the contestants who, in times of economic and work crisis, temporarily leave their careers to participate in the programme in the hope that it is a permanent departure. However, the profession of the contestants varies based on personal history, constantly presents a path of redemption, and so, for example, an Air Force sergeant, Alberico Nunziata, was one of the contestants of the first Italian edition; he said:

"For fifteen years I was forced to do something that was not mine, in the dullness of an office, in silence; I want to be in the kitchen, I want to hear the noise of the knife blade beating on the stove - the pots ... I want to smell the aromas and that is why we are here today at Masterchef: it represents the realisation of a path. As a teenager, I had some serious food issues, I ate continuously, and I weighed 190 pounds. In the end, partly as a joke, one of the many nutritionists who were around me gave me some advice....and said 'ah, try to cook' and, I swear, a world opened up and that is where all my creativity went, in a plate of macaroni. I wonder whether it could become my job? This would be my dream"8.

In the first US edition, Sharone Hakman had left his career as financial consultant to devote himself to cooking; in spite of not being awarded the title of first American Masterchef, three years later, the public media found him in a HSBC bank commercial ${ }^{9}$ and as the founder of a popular brand of barbecue sauce: the Haks sauce The product website states:

"He tested his creation; feeding bbq sauce-smothered steak to 500 Marines at Camp Pendleton, and satisfying America's road warriors with gourmet bbq burgers during a truck stop challenge. When TV's toughest food critics and chefs were blown away, Sharone knew it was time to share".10

So, in general, Masterchef is configured as a cultural product of a transnational middle class for which the rhetoric of self-made man seems, from the point of view of working practices, to conflict with the labour crisis context that has characterised the West in recent years.

However, if in the 2011 Italian edition and in the 2010 US edition, the economic crisis is hidden by the complex television and food mechanisms that Masterchef represents, the 2013 Spanish edition also seems to dish out the economic condition within which this cultural product was redesigned in the local reality. The apparent abundance of products and the barely concealed waste of food is not used during the tests the Spanish format constantly emphasises that leftover food will be donated to Caritas and, for each of the participants, it offers a year of spending at the supermarket sponsoring the transmission and appliances used by the contestant during the challenge. If in the India described by Appadurai, what is labelled as scrap or waste has a value packed with moral implications that refer to the

\footnotetext{
${ }^{7}$ As in one of the contestants of the Spanish edition was told: "La cocina son tres cosas: pasión, pasión y pasión." (Cooking consists of three things: passion, passion and passion.)

${ }^{8}$ Masterchef Italy, first season second episode. Minute 3:01 and following.

${ }^{9} \mathrm{http}: / /$ www.youtube.com/watch?v=41Jg_DN6S4g (last accessed 2 April 2015).

10 http://www.haksbbq.com/home.html (last accessed 15 October 2013).
} 
heart of traditional Hindu thinking, and if the cookbooks on the subject of his analysis often suggest a functional and creative reuse of what is discarded or uneaten, in Spain's economic crisis, leftover food is given a more symbolic meaning.

\section{Conclusions}

To conclude, based on the concepts of imagined communities and the invention of tradition, I tried to describe some of the meanings related to food and its consumption within the rhetoric built around food and its consumption and its waste in a television programme broadcast almost worldwide. I think the Masterchef format can represent an excellent arena for constructing symbolic meanings which, placing food in the spotlight, even clarify some aspects of the social fabric in terms of the imageries of the nation and work.

In the first editions of the Italian and US version of the program, very similar in terms of the narrative and the construction of the roles of the media, food preparation and the place in which it is prepared bring out a broader idea of how the media, the regional, multi-ethnic and national dimensions reflect some discourses on the nation. The final question I want to ask after these considerations has an exquisitely comparative flavour. As Masterchef is broadcast almost worldwide, and has quite a long history in television programming, I cannot avoid wondering how these media models are internalised and what values, symbols and imagery are fashioned in the daily life of the local television audience.

\section{References}

Anderson, B., (1983). Imagined communities: reflections on the origin and spread of nationalism, London: Verso [It. Ed. (2009). Comunità immaginate. Origine e fortuna dei nazionalismi. Roma: Manifestolibri].

Appadurai, A., (1988). How to make a national cuisine: cookbooks in the contemporary India in Comparative Studies in Society and History, Vol. 30 (1), 3-24.

Barberani, S., (2012). The Poetics of Food Consumption: Alimentary Rhetorics and Creative Practices. Mediterranean Journal of Social Sciences, Vol. 3 (7), 285-291.

Belasco, WJ., (1999) Why Food Matters in Culture and Agriculture, 21, 27-34.

Belasco, W.J. ; Scranton, J., (2002). Food Nation: Selling taste in consumer societies, London: Routledge.

Ciavolella, R., (2013). Antropologia politica e contemporaneità. Un'indagine critica sul potere. Milano: Mimesis.

Elias, N., (1978). The Civilizing Process, Oxford: Oxford University Press.

Fabietti, U., (2003). L'identità etnica. Storia e critica di un concetto equivoco, Milano: Carocci.

Ginsburg, F.D.; Abu-Lughod, L.;Larkin, B., (Eds.) (2002) Media Worlds Anthropology on New Terrain, Berkeley and Losa Angeles: University of California Press.

Goody, J., (1998). Food and Love. A Cultural History of East and West, London: Verso [It. Ed. (2012) Cibo e amore. Storia culturale dell'Oriente e dell'Occidente, Milano: Raffaello Cortina].

Herzfeld, M., (1997). Cultural Intimacy. Social poetics in the Nation-Sate, New York: Routledge [lt. Ed. (2003). Intimità Culturale. Antropologia e nazionalismo, Napoli: L'ancora del mediterraneo].

Hobsbawm, E.; Ranger, T., (Eds.)(1983). The Invention of Tradition, Cambridge: Cambridge University Press.

Lewis, T., (2011) 'You've put yourself on a plate' : the labour of selfhood on Masterchef Australia in Skeggs, B. ; Wood, H., (Eds.) Reality Television and Class, (pp. 104-116) London: Palgrave Macmillan.

Marrone, G., (2013). Cucinare senza senso. Strategie passionali e significazione spaziale in «Masterchef» in Studi Culturali 2, $235-252$.

Painter, A. A., (1994) On the Anthropology of Television: A Perspective from Japan. Visual Anthropology Review. Vol 10 (1) 70-84.

Remotti, F., (2001). Contro l'identità, Bari: Laterza.

Sennet, R., (2008). The Craftsman, Yale: Yale University Press [It. Ed. (2008). L’Uomo artigiano, Milano: Feltrinelli].

\section{Web sites}

http://www.youtube.com

http://www.fox.com/masterchef

http://www.rtve.es/television/masterchef

http://masterchef.sky.it

http://www.haksbbq.com 